\title{
Laryngeal mask insertion with a laryngoscope in paediatric patients
}

Purpose: To assess epiglottic position after laryngeal mask airway (LMA) insertion with or without the use of a laryngoscope.

Methods: A double-blind randomized study. In 48 children an LMA (\#2 for 6-20 kg, \#2.5 for 20-30 kg) was inserted eisher blindly or with the help of a laryngoscope and its position assessed using fibreoptic endoscopy.

Results: An unobstructed view of the glottis, as assessed by fibrescope, was observed in 10 of 25 patients in the laryngoscope group, but only in 1 of 22 patients in the blind insertion group $(P=0.005)$.

Conclusion: This technique offers an alternative when the standard technique has failed, or when LMA insertion precedes bronchoscopy or intubation via the laryngeal mask.

Objectif: Déterminer la position de l'épiglotte après l'insertion du masque laryngé (ML) avec ou sans laryngoscope.

Méthode: Etude aléatoire et en double aveugle. Chez 48 enfants, un masque laryngé ( $N^{n} 2$ pour les 6 à $20 \mathrm{~kg}, N^{n} 2,5$ pour les 20 à $30 \mathrm{~kg}$ ) a été inséré à l'aveugle ou avec un laryngoscope et sa position vérifiée par fibroscopie.

Résultats: La visualisation non obstruée de la glotte, vérifiée par fibroscopie, a été constatée chez 10 des 25 patients du groupe laryngoscopie, mais chez seulement un des 22 patients dans le groupe intubation à l'aveugle $(P=0,005)$.

\section{Key words}

AIRWAY: obstruction;

ANAESTHESIA: paediatric;

EQUIPMENT: masks, anaesthetic, LMA.

From the Department of Anaesthesia, Alberta Childrens Hospital, 1820 Richmond Road SW, Calgary, Alberta. Canada, T2T 5C7

Presented in abstract form at the 69th Clinical Congress of the International Anesthesia Rescarch Society, Honolulu, Hawaii.

Address correspondence to: Dr. R.G. Cox, Department of Anacsthesia, Alberta Childrens Hospital, 1820 Richmond Rd. SW, Calgary, Alberta T2T 5C7.

Phone: 403-229-7260. Fax: 403-229-7059.

Accepted for publication 3/st January, 1996.
Conclusion: Cette technique constitue une solution de rechange quand la technique standard a échoué ou quand l'insertion du ML précède une bronchoscopie ou une intubation à travers un $M L$.

Insertion of the laryngeal mask airway (LMA) using the inventors technique ${ }^{1,2}$ is a blind technique - the airway is not visualized during insertion. While even the novice user achieves $71-100 \%$ success, ${ }^{3-5}$ airway obstruction is encountered despite repeated attempts at insertion in 2-10\% of cases.Alternative insertion techniques are useful in these latter circumstances. While many alternative techniques to facilitate LMA insertion have been suggested, ${ }^{14-20}$ few have been tested prospectively . $^{6,21-3}$

Using a laryngoscope to help insert the $\mathrm{LMA}^{14.24 .25}$ opens the pharynx and elevates the epiglottis, providing a clear path for LMA insertion under direct vision. To assess final LMA position using these two techniques of LMA placement, we performed a prospective, randomized study in paediatric patients using fibreoptic evaluation of epiglottic position via the lumen of the LMA.

\section{Methods}

A sample size of 24 patients per group was estimated (alpha $=0.05$, (wo-tailed, beta $=0.2$ ) on the assumption that epiglottic displacement might decrease from the previously ${ }^{7}$ reported $50 \%$ to $10 \%$. After institutional ethics committee approval, consent was obtained in each case both by telephone ${ }^{26}$ and in writing from parents of children $(6-30 \mathrm{~kg}$ ) presenting for day-stay urological and lower abdominal surgery. Patients with pre-existing airway abnormalities and contraindications to LMA insertion ${ }^{20}$ were excluded. No premedication was given. Anaesthesia was induced with halothane $3-4 \%$ and nitrous oxide in oxygen by mask. Venous access was secured, and $10 \mu \mathrm{g} \cdot \mathrm{kg}^{-1}$ atropine iv were given, and caudal blockade $\left(1 \mathrm{ml} \cdot \mathrm{kg}^{-1}\right.$ bupivacaine $0.25 \%$ with adrenaline 1:200,000) was administered as indicated. Patients breathed $100 \% \mathrm{O}_{2}$ and halothane during administration of the caudal blockade for one to three minutes until the attending anaesthetist confirmed 
clinically that depth of anaesthesia was adequate for LMA insertion. The LMA was then inserted by one of two techniques in randomized order, according to sealed envelopes prepared using a random number table. A size \#2 LMA was used for children 6-20 kg; size \#2.5 for 20-30 kg. In the blind insertion group, the LMA was inserted using the inventors method' (sniffing position, jaw pulled down, index finger at tube-mask junction, aimed cephalad). In the laryngoscope group, a \#2 Macintosh laryngoscope was first inserted in the standard manner, then the LMA was inserted under direct vision. Patency of the airway was confirmed clinically by observing ( 1 ) synchronized movement of both the patients' chest and the anaesthetic reservoir bag with both spontaneous and positive pressure breaths, (2) by the lack of suprasternal or intercostal indrawing, (3) by auscultating air entry with gentle lung inflation, and (4) by observing the capnograph. All LMA insertions were performed by one investigator (RGC).

The second investigator (blinded to insertion technique) then assessed the airway using intraluminal fibreoptic endoscopy. The LMA was held to prevent movement during this examination. The fiberscopic view through the distal grille of the LMA was scored as one if the trachea was in line with the distal lumen of the LMA and there was a clear unobstructed view of the glottis. The view was scored as zero if the epiglottis was scen. The first investigator then repeated the examination, but could not change the score. Non-parametric variables were compared using the Mann-Whitney test, while dichotomous variables were compared using chi-square analysis or Fishers Exact test, where appropriate.

\section{Results}

The 47 patients ranged in age from 8 mo to $10 \mathrm{yr}$. Patient characteristics did not differ between the groups (Table). A perfect score was assigned in 10 of 25 patients in the laryngoscope group, but only in 1 of 22 patients in the blind insertion group $(P=0.005)$. The LMA was successfully inserted on the first attempt, with no clinical signs of obstruction occurring, except in one patient.. This patient, who was four years old, $14.5 \mathrm{~kg}$, and in the laryngoscope group, developed a kink in the tube portion of the LMA which required minor repositioning. Interestingly, a difficult LMA insertion had been recorded during his previous anaesthetic. The investigators did not disagree on the score assigned to any of the patients.

\section{Discussion}

We found that the best score for epiglottic position was obtained more frequently when a laryngoscope was used to insert the LMA.
TABLE Patient demographics and results. Values are expressed as median (interquartile rangc) where appropriate.

\begin{tabular}{|c|c|c|}
\hline & Laryngoscope group & Blind insertion group \\
\hline Age $(y r)$ & $2.9(1.9-4.0)$ & $3.5(0.7-5.0)$ \\
\hline Weight (kg) & $14(12-16)$ & $15(9-20)$ \\
\hline Male scx & 19 of 25 & 20 of 22 \\
\hline Perfect endoscopic scorc & 10 of $25^{*}$ & 1 of 22 \\
\hline
\end{tabular}

$* P=0.004$ (chi-square).

Many letters to the editor have recounted improved success inserting the LMA when an alternative technique was used (completely or partially inflating the mask, lifting the mandible, rotating the mask or sliding it over a spoon, or curling the tip). ${ }^{14-20}$ The improved success rate over time may simply represent a comparison with historical controls, and would have occurred with or without adopting each new technique. Fibreoptic assessment of LMA position is a proven assessment technique. ${ }^{7,27.28}$ Radiological means to assess LMA posi$\operatorname{tion}^{29}$ were not justified in this study. We also found that subdividing airway scores based on a partially or completely downfolded epiglottis ${ }^{7}$ was arbitrary, with considerable inter-rater differences, and we therefore chose to use dichotomous scoring.

Distortion of the airway with epiglottic downfolding occurs in $50-90 \%$ of patients ${ }^{9,29}$ after LMA placement. Children may be particularly prone to epiglottic displacement because of their relatively larger epiglottis, ${ }^{25}$ or the differing shapes of both the paediatric LMA and the paediatric laryn $x^{17}$ compared with that of the adult.

Children are also particularly prone to laryngospasm with stimulation of airway structures, although laryngospasm was not observed in any of our patients. Downfolding of the epiglottis may reflect a more traumatic LMA insertion, with more of a propensity to laryngospasm than when the epiglottis is undisplaced. An epiglottis that is completely folded down does not obstruct the airway per se, as airflow can continue around the lateral margins of the epiglottis. ${ }^{30}$ This probably accounts for the low incidence of clinical airway obstruction in this study. Using a laryngoscope to insert the LMA may increase the haemodynamic stress reponse, ${ }^{31}$ and can be argued to either increase ${ }^{32}$ or decrease $^{22}$ the potential for airway trauma.

When the laryngeal mask is being inserted for purposes of either bronchoscopy ${ }^{33}$ or tracheal intubation ${ }^{8.34}$ the path projecting beyond the LMA lumen should not be obstructed. The use of a laryngoscope as we have described is an important alternative technique when the blind insertion technique has failed, or as a primary 
technique when LMA insertion precedes passage of a bronchoscope or endotracheal tube through its lumen.

\section{Acknowledgment}

The authors wish to thank Dr. Dele Davies, Department of Paediatrics, Alberta Childrens Hospital, for assistance with the statistical analysis.

\section{References}

1 Brain AIJ. The intavent laryngeal mask instruction manual, 2nd ed. Reading, Bcrkshire: Intavent Ltd., 1991.

2 Brain A. Proper technique for insertion of the laryngeal mask (Letter). Ancsthesiology 1990; 73: 1053.

3 Baskett PJF et al. (members of the study group). The use of the laryngeal mask airway by nurses during cardiopulmonary resuscitation. Results of a multicentre trial. Anaesthesia 1994; 49: 3-7.

4 Davies PRF, Tighe SQM, Greenslade GL, Evans GH. Laryngeal mask airway and tracheal tube insertion by unskilled personnel. Lancet 1990, 336; 977-9.

5 Paterson SJ, Byrne PJ, Molesky MG, Seal RF, Finucane $B T$. Neonatal resuscitation using the laryngeal mask airway. Anesthesiology 1994; 80: 1248-53.

6 O'Neill B, Caramico L, Templeton JJ, Schreiner MS. Inflated vs. deflated insertion of the laryngeal mask airway in infants and children. Anesthesiology 1993; 79; Al188.

7 Rowbottom SJ, Simpson DL, Grubb D. The laryngeal mask airway in children. A fibreoptic assessment of positioning. Anaesthesia 1991; 46: 489-91.

8 Wilson $I G$. The laryngeal mask airway in paediatric practice (Editorial). Br J Anaesth 1993; 70: 124-5.

9 Benumof $J L$. Laryngeal mask airway. Indications and contraindications (Editorial). Anesthesiology 1992; 77 : 843-6.

10 Smith $I$, White $P F$. Use of the laryngeal mask airway as an alternative to a face mask during outpatient arthroscopy. Anesthesiology 1992; 77: 850-5.

11 Maltby JR, Loken $R G$, Watson $N C$. The laryngeal mask airway: clinical appraisal in 250 patients. Can J Anaesth 1990; 37: 509-13.

12 Mason DG, Bingham RM. The laryngeal mask airway in children. Anaesthesia 1990; 45: 760-3.

13 Brodrick PM, Webster NR, Nunn JF. The laryngeal mask airway. A study of 100 patients during spontaneous breathing. Anaesthesia 1989; 44: 238-41.

14 Lee JJ. Laryngeal mask and trauma to uvula (Letter). Anaesthesia 1989; 44: 1014.

15 Leader GL. Facilitation of the insertion of the laryngeal mask (Letter). Anaesthesia 1991; 46: 987.

16 Newman PTF. Insertion of a partially inflated laryngeal mask airway (Letter). Anaesthesia 1991; 46: 235.

17 McNicol LR. Insertion of laryngeal mask airway in children (Letter). Anaesthesia 1991; 46: 330.
18 Cino PJ, Webster AC. Laryngeal mask insertion - a useful tip (Letter). Anaesthesia 1993; 48: 1012.

19 Harding JB. A 'skid' for easier insertion of the laryngeal mask airway (Letter). Anaesthesia 1993; 48: 80.

20 Rabenstein $K$. Alternative techniques for laryngeal mask insertion (Letter). Anaesthesia 1994; 49: 80-1.

21 Brimacombe J, Berry A. Insertion of the laryngeal mask airway - a prospective study of four techniques. Anaesth Intensive Care 1993; 21: 89-92.

22 Dingley J, Whitehead MJ, Wareham K. A comparative study of the incidence of sore throat with the laryngeal mask airway. Anaesthesia 1994; 49: 251-4.

23 ONeill B, Templeion JJ, Caramico L, Schreiner MS. The laryngeal mask airway in pediatric patients: factors affecting ease of use during insertion and emergence. Anesth Analg 1994; 78: 659-62.

24 Jenkins $J$. The laryngoscope and the laryngeal mask airway (Letter). Anaesthesia 1993; 48: 735.

25 Chow BFM, Lewis $M$, Jones SEF. Laryngeal mask airway in children: insertion technique (Letter). Anaesthesia 1991; 46: $590-1$.

26 Maltby $J R$, Eagle $C J$. Informed consent for clinical anaesthesia research. Can J Anaesth 1993; 40: 891-6.

27 Payne J. The use of the fibreoptic laryngoscope to confirm the position of the laryngeal mask (Letter). Anacsthesia $1989 ; 44: 865$.

28 Monso E, Carreras A, Bassons J, Gonzalez-Tadeo M. Fibreoptic laryngoscopy as a method of assessing the risk of airway obstruction following laryngeal mask airway insertion (Letter). Anaesthesia 1992; 47: 631-2.

29 Goudsouzian NG, Denman W, Cleveland R, Shorten $G$. Radiologic localization of the laryngeal mask airway in children. Ancsthesiology 1992; 77: 1085-9.

$30 \mathrm{Brain}$ AlJ. Studies on the laryngeal mask: first, learn the art (Letter). Anaesthesia 1991; 46: 417-8.

31 Wilson IG, Fell D, Robinson SL, Smith G. Cardiovascular responses to insertion of the laryngeal mask. Anaesthesia 1992; 47: 300-2.

32 Brimacombe J, Berry $A$. The laryngoscope and the laryngeal mask airway (Letter). Anaesthesia 1994; 49: 82.

33 Dich-Nielsen JO, Nagel P. Flexible fibreoptic bronchoscopy via the laryngeal mask. Acla Anaesthesiol Scand 1993; 37: 17-9.

34 Brimacombe .J, Berry A. Laryngeal mask airway insertion - which way is best and what should we teach? (Letter) Anaesth Intensive Care 1993; 21 : 897-8. 